\title{
Pleomorphic Adenoma of Three Different Sites: a Consecutive Case Series
}

\author{
Felice FAIZAL ${ }^{1}$, Ankur AHUJA ${ }^{1}$, R. CHATTERJEE ${ }^{1}$
}

\begin{abstract}
Background: Pleomorphic adenomas are benign salivary gland tumors predominantly arising from the superficial lobe of the parotid gland and rarely from the small salivary glands located at various locations including parotid, lacrimal duct, lip, floor of the mouth etc. Surgical excision of the tumor mass is the treatment of choice with utmost care taken to preserve the facial nerve in cases involving the parotid gland. Case details: This case series highlights three consecutive cases of pleomorphic adenoma arising from three different locations. Conclusion: Pleomorphic adenoma is the commonest salivary gland tumor characterized by diverse histomorphological features and can occur at any site where salivary tissue is present. Careful histopathological analysis should be done in all tumors arising especially in the head and neck region.
\end{abstract}

Keywords: Benign salivary gland tumors, pleomorphic adenomas, parotidectomy.

\section{INTRODUCTION}

Pleomorphic adenoma (PA), also known as benign mixed tumor, is the most common type among benign tumors of salivary glands and majority of them arise in the parotid gland followed by the submandibular gland. Only $10 \%$ of the PAs originate from the small salivary glands, and can develop at any site where these glands are located, including the palate, upper lip, floor of the mouth, lacrimal gland, larynx, and trachea ${ }^{1-3}$.

In this case series we report three consecutive cases of pleomorphic adenoma diagnosed at our hospital, each arising at a different location.

\section{CASE 1}

A 41-year-old male presented to the ophthalmology department with a swelling below the medial canthus of the left eye. The painless swelling was diagnosed cli- nically as a sebaceous cyst and referred for a FNAC. On cytology, the cellular smears were composed of benign epithelioid and plasmacytoid cells arranged in sheets and clusters with variable amounts of myxoid stroma.A probable diagnosis of pleomorphic adenoma was made on cytology.

The mass was consequently surgically excised as there were no signs of duct obstruction warranting a dacrocystorhinostomy. On gross examination, the entire mass composed of a bosselated tumor with myxoid appearance. Histopathology revealed an encapsulated tumor showing a few ductal epithelial cells and abundant plasmacytoid cells in sheets amidst a chondromyxoid stroma (Figure 1).

In view of the site and the histological features, a diagnosis of pleomorphic adenoma of the lacrimal duct was made. The patient is currently under uneventful follow up. 


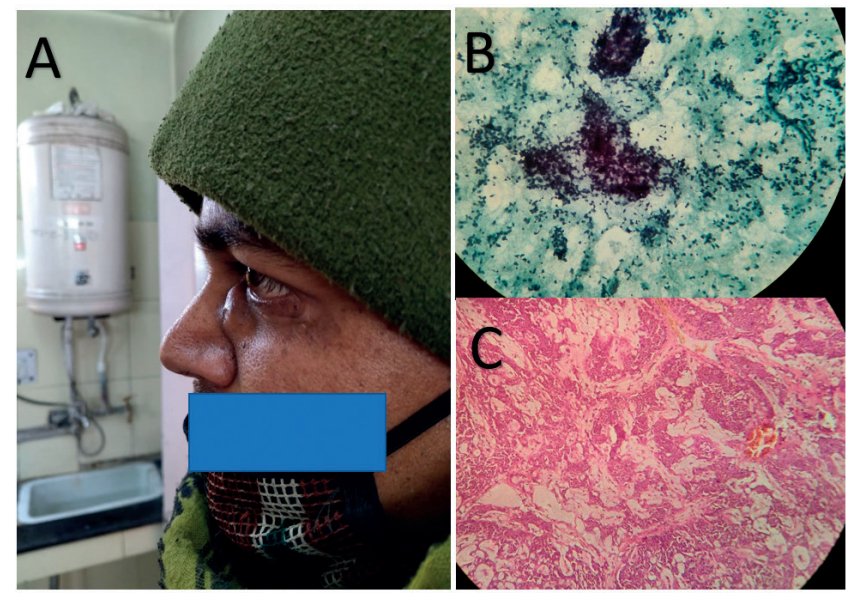

Figure 1. Pleomorphic adenoma nasolacrimal duct. A: Clinical picture of a young male showing a tumor below the left medial canthus. B: PAP stained FNAC smear from the mass shows benign epithelioid and plasmacytoid cells arranged in sheets and clusters with variable amounts of myxoid stroma. C: Histopathology shows an encapsulated tumor with ductal epithelial cells and abundant plasmacytoid cells in sheets amidst a chondromyxoid stroma

\section{CASE 2}

37-year-old male reported with a submandibular swelling and was diagnosed clinically as a submandibular cyst. The cyst was excised and specimen sent to our centre for histopathology.

On gross examination, the specimen measured $5 \times 4 \times 3 \mathrm{~cm}$ with a congested periphery and gray white myxoid area in the centre. Histopathological examination revealed normal salivary gland in the periphery with an encapsulated tumor composed of epithelial and myoepithelial cells in a myxomatous stroma (Figure 2). The tumor was diagnosed as a benign mixed salivary gland tumor and the patient is on uneventful follow up.

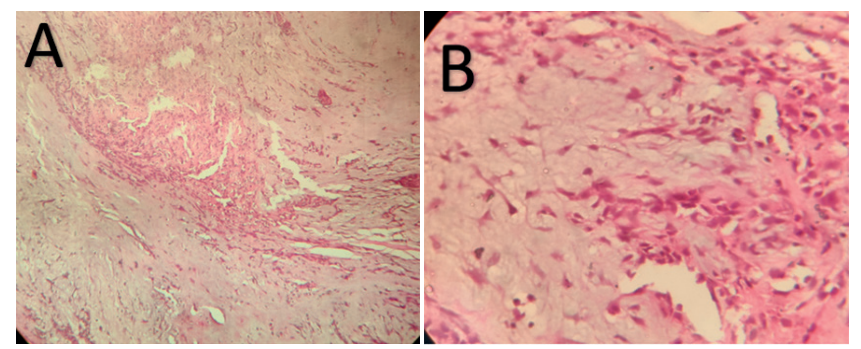

Figure 2. Submandibular gland Pleomorphic adenoma. A: 100X histopathology shows ductal epithelial cells and chondromyxoid stroma. B: $400 \mathrm{X}$ magnification highlighting the benign features of the tumor

\section{CASE 3}

A 32-year-old male presented with a large painless and firm mass in the left parotid region with a history of a similar mass in the same region seven years ago which was surgically excised. However no written records of the surgery or the nature of the previous mass were available.

The patient was referred for a FNAC and cytology showed a cellular smear with plenty of myoepithelial cells in sheets with abundant fibrillary myxoid background. Dyscohesive epithelial cells showing high nuclear cytoplasmic ratio, irregular nuclear borders and prominent nucleoli were also noted. Considering the history and degree of atypia, a probable diagnosis of pleomorphic adenoma was made on cytology with a tissue biopsy advised to rule out carcinoma ex pleomorphica (Ca-ex-PA).

A total parotidectomy was performed along with excision of a lymph node located in the deep lobe. On gross examination, a bosselated gray white tumor was located in the superficial lobe which was soft to firm in consistency. The deep lobe and lymph node did not show any gross involvement. On histology, the tumor showed a mixed proliferation of ductal epithelial and myoepithelial cells embedded in a myxomatous stroma. The epithelial cells showed varying degrees of nucleocytoplasmic ratio but no mitosis or necrosis was noted. All surgical margins and the lymph node were free of tumor (Figure 3). The tumor was hence diagnosed as a case of pleomorphic adenoma and the patient is on regular follow up.

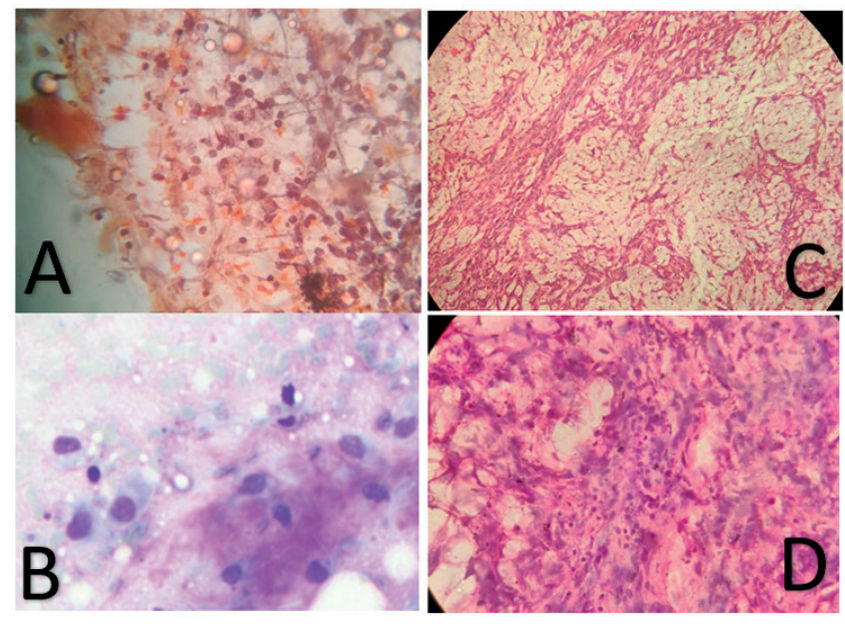

Figure 3. Recurrent pleomorphic adenoma parotid gland A:FNAC from the parotid mass shows ductal epithelial cells and chondromyxoid stroma. B: Few areas show dyscohesive cells with high N/C ratio on cytology. C,D: 100X and 400X Histopathology shows no features of malignancy. 


\section{DISCUSSION}

Tumors of the lacrimal system are rare and pose a diagnostic dilemma as a very low percentage of these tumors resulting in lacrimal obstruction.,5,6 Among them, pleomorphic adenomas, which is the most common epithelial tumor to arise from the lacrimal gland can also originate from the glandular structures present in the walls of the lacrimal sac and nasolacrimal duct ${ }^{7,8,9}$. Involvement of the nasolacrimal duct and the lacrimal sac by PA has been mentioned in literature with reported cases of malignant transformation to carcinoma ex pleomorphic adenoma arising from the nasolacrimal duct and lacrimal gland ${ }^{10-14}$.

In our first case, the unusual site had resulted in the clinical diagnosis of a sebaceous cyst and preoperative FNAC suggested PA which was confirmed on histopathology following enucleation of the tumor. This highlights the importance of preprocedural cytology to better guide patient management.

Histologically, the tumor was composed of ductules lined by benign epithelial cells, abundant plasmacytoid cells in sheets and focal myxoid stroma. The plasmacytoid cells are traditionally considered to be modified neoplastic myoepithelial cells but recent studies suggest a different origin with epithelial-mesenchymal transformation resulting in this particular phenotype $\mathrm{e}^{15}$. Even though external Dacrocystorhinostomy (DCR) is regarded as the gold standard in terms of surgical success in cases presenting with duct obstruction, Benign epithelial lacrimal system tumors are often managed by external or endoscopic dacrocystorhinostomy and simple excision of the mass with comparable results. ${ }^{16}$. The external approach has an added advantage of better inspection of the lacrimal sac.

Our patient had a benign mixed tumor and no signs of duct obstruction and therefore was managed with complete excision of the mass along with the capsule. The patient is on regular follow-up and has shown no signs of recurrence till date.

The submandibular gland is the second most common site of PA after the parotid gland and PA is also the most frequent benign tumor arising in submandibular gland. ${ }^{17,18}$ Submandibular swellings pose a diagnostic challenge as the differential diagnosis includes lymphadenitis, sialadenitis, lymphoepithelial, basal cell adenoma, adenocarcinoma, mucoepidermoid carcinoma and lymphoma.

Similarly in our case a 37-year-old male presenting with a submandibular swelling was diagnosed clinically as a submandibular cyst. The mass was excised and sent for histopathology to our hospital due to unavailability of FNAC at the peripheral hospital. The tumor was diagnosed as a benign mixed tumor of the salivary gland and the patient is under uneventful follow up. Even though the recurrence of submandibular PAs is rare when compared to parotid tumors, incomplete removal of the glandular tissue may lead to the same ${ }^{19,20}$.

In the parotid gland,Pleomorphic adenoma is the most common benign tumor and has a female preponderance with maximum incidence in the 30-60 years age group. Although it presents as a slow-growing tumor, it may become malignant in upto 25 percent of the cases ${ }^{21,22}$.

Pleomorphic adenoma is characterized by the presence of microscopic extensions protruding beyond the pseudocapsule and existence of satellite lesions surrounding the capsule which is responsible for recurrence. Simple enucleation of pleomorphic adenoma is associated with high recurrence rates which is markedly reduced by superficial or total parotidectomy ${ }^{23}$.

$\mathrm{Ca}-\mathrm{ex}-\mathrm{PA}$ is a carcinoma originating either from a primary or recurrent benign pleomorphic adeno$\mathrm{ma}^{24}$. The exact pathogenesis of $\mathrm{Ca}-\mathrm{ex}-\mathrm{PA}$ is debated as some authors state that they are malignant from the onset whereas some consider it to be a carcinomatous transformation of a mixed tumor. ${ }^{25}$ Preoperative misdiagnosis is common in these tumors as the features depend on the relative proportion of the adenoma and carcinoma components. A high index of suspicion and thorough sampling is required to make a definitive diagnosis.

In our case, the past history of mass at same location, and the cytological findings of few atypical cells warranted a warning to look out for $\mathrm{Ca}$-ex-PA. The clinical overlap along with cytological variations and mild atypia on smears from pleomorphic adenoma have been reported to cause diagnostic dilemmas on FNAC in cases of $\mathrm{Ca}-\mathrm{ex}-\mathrm{PA}^{26}$.

\section{CONCLUSION}

Pleomorphic adenomas have been reported in major and minor salivary glands at unusual locations and every mass especially in the head and neck region should be evaluated with a high degree of suspicion with pre-operative FNAC whenever possible. Wide excision should be performed due to the high rate of recurrence of this tumor. 
Compliance with ethics requirements: The authors declare no conflict of interest regarding this article. The authors declare that all the procedures and experiments of this study respect the ethical standards in the Helsinki Declaration of 1975, as revised in 2008(5), as well as the national law. Informed consent was obtained from all the patients included in the study.

\section{References}

1. Manucha $\mathrm{V}$, loffe OB. Metastasizing pleomorphic adenoma of the salivary gland. Arch Pathol Lab Med. 2008;132(9):1445-1447. doi:10.1043/1543-2165(2008)132[1445:MPAOTS]2.0.C0;2

2. Unlu HH, Celik O, Demir MA, Eskiizmir G. Pleomorphic adenoma originated from the inferior nasal turbinate. Auris Nasus Larynx. 2003;30(4):417-420

3. Pons Vicente O, Almendros Marques N, Berini Aytes L, Gay Escoda C. Minor salivary gland tumors: a clinicopathological study of 18 cases. Med Oral Patol Oral Cir Bucal. 2008;13(9):E582-E588.

4. Parmar DN, Rose GE. Management of lacrimal sac tumours. Eye (Lond) 2003;17:599-606. Back to cited text no. 1

5. Ryan SJ, Font RL. Primary epithelial neoplasms of the lacrimal sac. Am J Ophthalmol 1973;76:73-88

6. Anderson NG, Wojno TH, Grossniklaus HE. Clinicopathologic findings from lacrimal sac biopsy specimens obtained during dacryocystorhinostomy. Ophthalmic Plast Reconstr Surg. 2003;19(3):173-176. doi:10.1097/01.IOP .0000066646.59045.5A

7. Heindl LM, Jünemann AG, Kruse FE, Holbach LM. Tumors of the lacrimal drainage system. Orbit 2010;29:298-306

8. Pe'er J, Hidayat AA, Ilsar M, Landau L, Stefanyszyn MA. Glandular tumors of the lacrimal sac. Their histopathologic patterns and possible origins. Ophthalmology 1996;103:1601-5.

9. Shields JA, Shields CL, Scartozzi R. Survey of 1264 patients with orbital tumors and simulating lesions: The 2002 montgomery lecture, part 1. Ophthalmology 2004;111:997-1008

10. Lee JS, Lee H, Chang M, Park M, Baek S. Benign mixed tumor of the lacrimal sac. Indian J Ophthalmol. 2015;63(3):282-284. doi:10.4103/0301-4738.156940

11. Baredes S, Ludwin DB, Troublefield YL, Langer PD, Mirani N. Adenocarcinoma ex-pleomorphic adenoma of the lacrimal sac and nasolacrimal duct: a case report. Laryngoscope. 2003;113(6):940942. doi:10.1097/00005537-200306000-00005

12. Harrison W, Pittman P, Cummings T. Pleomorphic adenoma of the lacrimal gland: A review with updates on malignant transformation and molecular genetics. Saudi J Ophthalmol. 2018;32(1):1316. doi:10.1016/j.sjopt.2018.02.014

13. Haft SJ, Jafari A, Lowenthal BM, Korn BS, DeConde AS. Pleomorphic Adenoma of the Nasolacrimal Duct. JAMA Otolaryngol Head Neck Surg. 2018;144(9):849-851. doi:10.1001/jamaoto. 2018.1448

14. Vamsee K. Neerukonda, Bryant Carruth, Maria Del Valle Estopinal, "Invasive Carcinoma Ex-Pleomorphic Adenoma of the Lacrimal Gland with a Cystadenocarcinoma Component: A Case Report and Review of the Literature", Case Reports in Pathology, vol. 2020, Article ID 6482837, 6 pages, 2020. https://doi. org/10.1155/2020/648283715. Ioannis G. Koutlas, Michelle Dolan, Mark W. Lingen, Prokopios P. Argyris,
Plasmacytoid cells in salivary pleomorphic adenoma: an alternative interpretation of their immunohistochemical characteristics highlights function and capability for epithelial-mesenchymal transition,Oral Surgery, Oral Medicine, Oral Pathology and Oral Radiology,Volume 128, Issue 5,2019,Pages 515-529,ISSN 2212-4403,https://doi.org/10.1016/j.0000.2019.01.081.

16. Savino G, Battendieri R, Traina S, et al. External vs. endonasal dacryocystorhinostomy: has the current view changed? Acta Otorhinolaryngol Ital. 2014;34(1):29-35

17. Laskawi R, Ellis M, Arglebe C, Schott A. Surgical management of benign tumors of the submandibular gland: A follow-up study. $J$ Oral Maxillofac Surg. 1995;53:506-8.

18. Illes RW, Brian MB. A review of the tumors of the salivary gland. Surg Gynecol Obstet. 1986;163:399-4.

19. Molina EJ, Mayer K, Khurana J, Grewal H. Pleomorphic adenoma of the submandibular gland. J Pediatr Surg 2008;43:1224-6.

20. Munir N, Bradley PJ. Pleomorphic adenoma of the submandibular gland: An evolving change in practice following review of a personal case series. Eur Arch Otorhinolaryngol 2007;264:1447-52.

21. Mendenhall WM, Mendenhall CM, Werning JW, Malyapa RS, Mendenhall NP. Salivary gland pleomorphic adenoma. Am J Clin Oncol. 2008;31:95-99.

22. Zbaren P, Tschumi I, Nuyens M, Stauffer E. Recurrent pleomorphic adenoma of the parotid gland. Am J Surg. 2005;189:203-207.

23. Wittekindt C, Streubel K, Arnold G, Stennert E, Guntinas-Lichius O. Recurrent pleomorphic adenoma of the parotid gland: analysis of 108 consecutive patients. Head Neck. 2007;29:822-828

24. Nouraei SA, Hope KL, Kelly CG, McLean NR, Soames JV. Carcinoma ex benign pleomorphic adenoma of the parotid gland. Plast Reconstr Surg. 2005;116:1206-13

25. Olsen KD, Lewis JE. Carcinoma ex pleomorphic adenoma: A clinicopathologic review. Head Neck. 2001;23:705-12

26. Kim HJ. Fine needle aspiration cytology finding of a parotid mass with chondromyxoid matrix and variable epithelial cytological atypia. Cytojournal. 2018;15:10. Published 2018 Apr 2. doi:10.4103/cytojournal.cytojournal_25_17

27. Handa U, Dhingra N, Chopra R, Mohan H. Pleomorphic adenoma: Cytologic variation and potential diagnostic pitfalls. Diagn Cytopathol. 2009;37:11-5. 